\title{
DRUG INTERACTIONS IN EPILEPSY
}

\author{
EMILIO PERUCCA, M.D.*
}

Despite present trends in favour of a single drug for the treatment of epilepsy many patients still receive a combination of at least two antiepileptic drugs. When combined therapy is used, interactions may occur which can result in a modification of the dose-response relationship: this, in turn, can be responsible for therapeutic failure in some cases and exaggerated response (toxicity) in others. Interactions between antiepileptic drugs, or between anticpileptic drugs and other drugs, are a frequent occurrence. It is the purpose of this article to outline some of the more important from the clinical point of view. For more complete information and for a source of references the reader is referred to other available reviews (Kutt, 1972; Richens, 1977; Perucca and Richens, 1979; Perucca, 1979).

\section{INTERACTIONS AFFECTING HANDLING AND RESPONSE TO ANTIEPILEPTIC DRUGS}

Absorption interactions - Antacids such as magnesium and aluminium hydroxide can reduce the gastrointestinal absorption of phenytoin, barbiturates and some benzodiazepine drugs. In order to minimize the risk of interactions, it is probably wise to recommend that antiepileptic drugs be administered at least two to three hours prior to the ingestion of antacids.

Plasma protein binding interactions - Phenytoin is extensively bound to plasma proteins. Drugs with high binding affinity can compete with phenytoin at its binding sites and therefore increase its free (unbound) fraction in plasma. Table 1 lists a number of agents which have been shown to displace phenytoin from plasma protein binding sites in vitro or in vivo. Since only the unbound drug is available to produce a pharmacological response, displacement could theoretically be expected to result in enhanced therapeutic and toxic effects. However, this prediction does not strictly apply to a drug which, like phenytoin, has a relatively large volume of distribution. In the latter case, the amount of drug in plasma is small compared with the total amount in the body, and even marked displacement with consequent shift of drug from plasma to tissues will have only little influence on the drug concentration at the receptor site.

The most important of the interactions listed in Table 1 occurs between phenytoin and valproic acid. Following administration of valproic acid to epileptic

- Research Fellow and Clinical Assistant, Institute of Neurology, The National Hospital, Qu sen Square, London WC1N 3BG, England. 
patients stabilized on phenytoin terapy, a considerable fraction of phenytoin is displaced from plasma proteins and diffuses into tissues: as a result, the concentration of total phenytoin in plasma is markedly reduced (Mattson et al, 1978). However, despite the marked fall in total drug concentration, the free plasma phenytoin concentration is not reduced (in fact it may be slightly raised), the therapeutic response is unaffected or even slightly enhanced and the dosage may not need to be increased (Mattson et al, 1978). These principles should be kept in mind when interpreting serum phenytoin levels in presence of a displacing drug: due to the reduced degree of protein binding, the therapeutic range will be shifted towards considerably lower values.

\begin{tabular}{l||l}
\hline Phenylbutazone & Valproic acid \\
Salicylic acid & Tolbutamide \\
Diazoxide & Halofenate \\
\hline
\end{tabular}

Table 1 - Drugs which have been shown to displace phenytoin from plasma protein binding sites.

Inhibition of metabolism - Phenytoin metabolism is extremely vulnerable to inhibition by other drugs. Because of the saturable nature of phenytoin kinetics, a small degreee of inhibition can result in a disproportionate rise of the serum concentration of the drug at steady state, and clinical intoxication is likely to occur.

In the early sixties, many physicians used to comment on the unusual sensitivity of tuberculotic patients to the toxic effects of phenytoin. The possibility of a drug interaction occurring in these patients was first considered when Murray (1962) reported the occurrence of marked drowsiness and unsteadniness of gait in 70 out 637 institutionalized epileptics who were given isoniazid for the prophylaxis of tuberculosis. It is now well known that isoniazid is one of the most powerful inhibitors of phenytoin metabolism: when isoniazid is given to epileptic patients, in a substantial proportion of cases the serum phenytoin will rise markedly (Fig. 1) and intoxication will almost invariably occur in those patients in whom the phenytoin concentration in serum was already reasonably high prior to the addition of the interfering drug. Interestingly, slow acetylators (approximately 60 per cent of Caucasians) are very much more vulnerable to this interaction than fast acetylators, perhaps because only the former subjects achieve an hepatic concentration of isoniazid sufficiently high to inhibit phenytoin metabolism (Kutt, 1972). In vitro, and possibly in vivo, the isoniazid-induced inhibition of phenytoin metabolism is markedly potentiated by p-amino-salicylic acid (PAS), which is frequently associated in antituberculous therapy: since isoniazid and phenytoin can produce similar mani- 


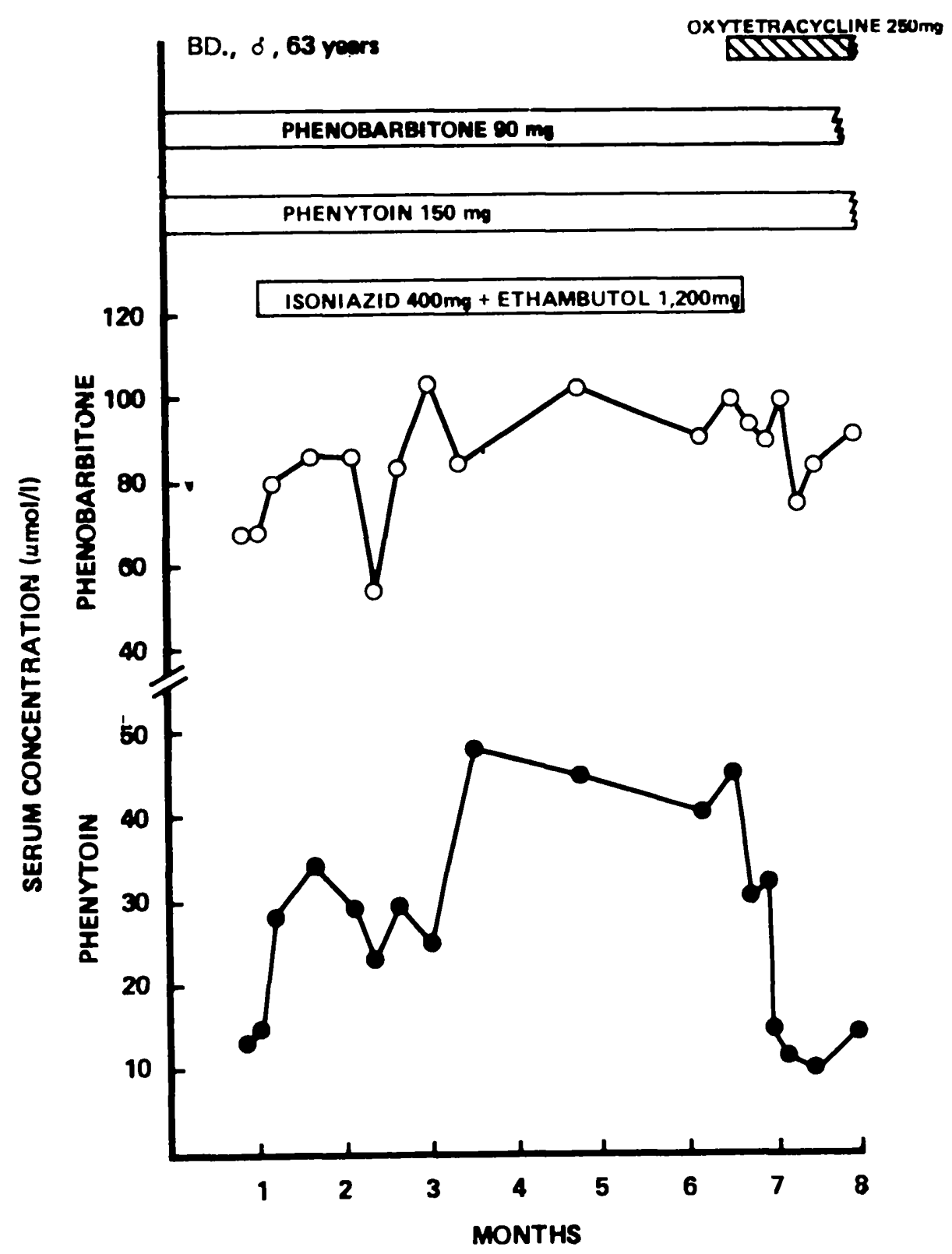

Fig. 1 - Effect of adding isoniasid to te therapeutic regime of an epileptic patient stabilized on phenytoin and phenobarbitone therapy. Note the marked increase in serum phenytoin levels during antituberculous treatment. (Reproduced from Perucca and Richens, 1979, with permission).

festations of central nervous system toxicity, the diagnosis of phenytoin intoxication may not be readily recognized especially when the clinician is unaware of the interaction and facilities for monitoring serum phenytoin levels are not available.

Apart from isoniazid, many other drugs have been reported to raise phentyoin levels and/or precipitate phenytoin intoxication in patients (Table 2): the lenght of the list (which is not exhaustive) clearly emphasizes the need for suspecting the possibility of this type of interation whenever signs consistent with phenytoin intoxication develop in patients started on other drugs. Some of these interactions are very inconsistent. However, the clinician needs to be aware at least of the most common and consistent: apart from isoniazid, this 


\begin{tabular}{l||l||l}
\hline Sulthiame & Chloramphenicol & Methylphenidate \\
Pheneturide & Phenyramidol & Chlorpheniramine \\
Isoniazid & Various sulfonamides & Phenobarbitons * \\
Dicoumarol & Imipramine & Benzodiazepines \\
Phencoupromon & Chlorpromazine & Methylsuximide \\
Disulfiram & Propoxyphene & Trimethoprin \\
\hline
\end{tabular}

Table 2-Drugs which can inhibit phenytoin metabolism, increase serum phenytoin levels and precipitate pherytoin intoxication in patients: evidence is controversial for these drugs.

list should probably include sulthiame, chloramphenicol, pheneturide and dicoumarol. The interaction with sulthiame is particularly important because this drug is sometimes associatd with phenytoin in the treatment of epilepsy. Amongst a large number of patients admited to the Chalfont Centre for Epilepsy, the serum concentration of phenytoin was on average 74 per cent higher in patients receiving sulthiame than in a similar group of patients receiving equivalent phenytoin doses but not sulthiame in combination (Houghton and Richens, 1974). Clinical signs of intoxication were almost four times as common in the former group. This interaction appears to be quite consistent, and the suggestion has been made that the antiepileptic activity of sulthiame could in fact be entirely mediated by its elevating effect on serum phenytoin levels. A typical example of this effect is illustrated in Figure 2. There is usually a latent period of

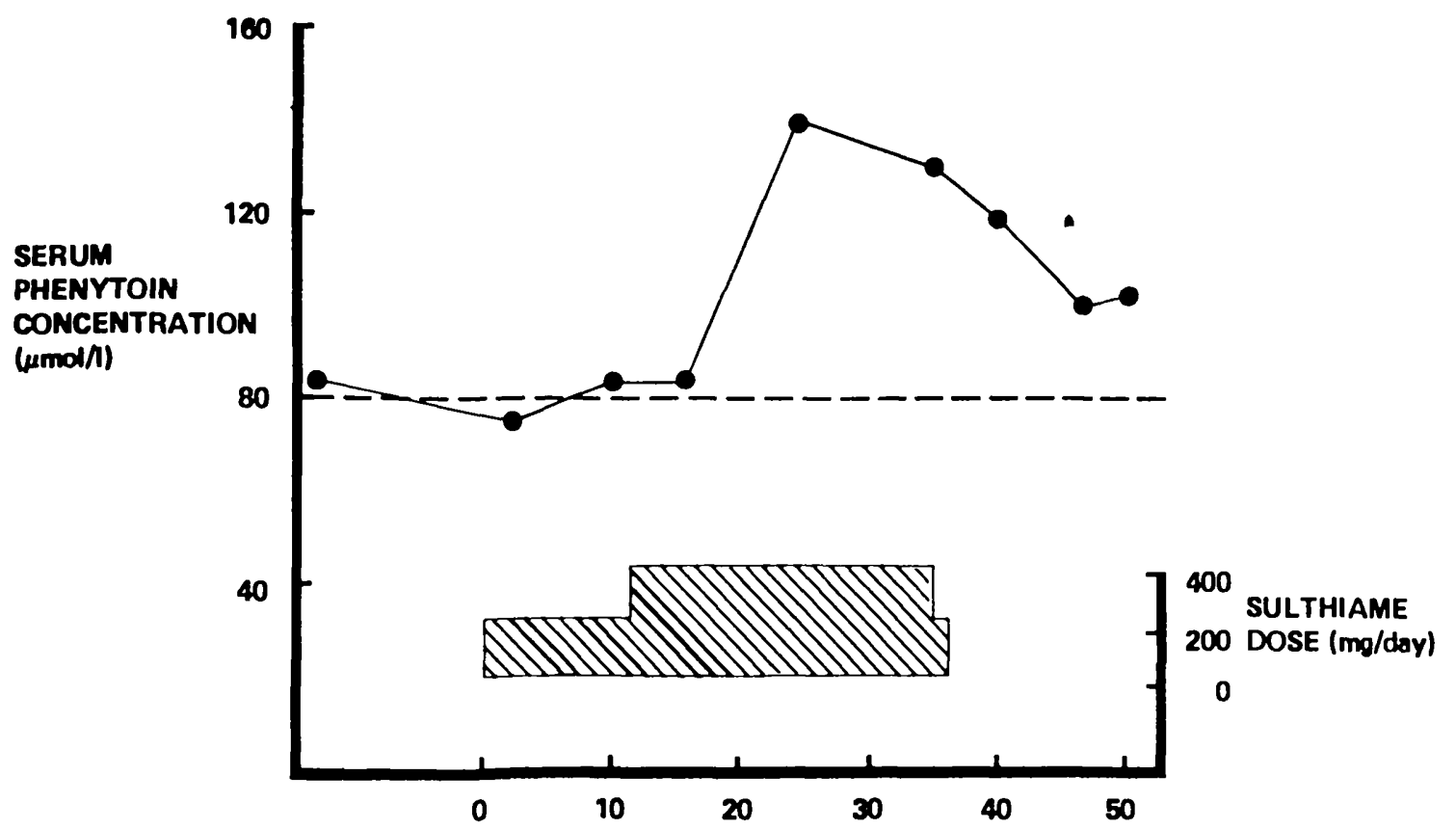

F'ig. \& - Effect of adding sulthiame to the therapoutic regime of an epileptic patient stabilized on chronic articonvulsant therapy. Note the delayed marlced rise in sorum phenytoin levels after starting sulthiame. 
ten to twenty days between the addition of sulthiame and the subsequent rise in serum phenytoin concentration. This outlines the necessity for prolonged observation and serum phenytoin level monitoring in patients started on the combination.

Other drugs - The metabolism of phenobarbitone, primidone, carbamazepine, valproic acid, diazepam and clonazepam is less susceptible to being inhibited by other drugs (Table 3). The most common interaction involving these drugs is probably the inhibition of phenobarbitone metabolism by valproic acid. Serum phenobarbitone levels increase by approximately 30 per cent on average when valproic acid is started in combination; the magnitude of the interaction, however, varies considerably from one patient to another. In many patients, the rise in serum phenobarbitone concentration is sufficiently marked to account for the drowsiness and sedation which are frequently observed during the initial stages of valproic acid therapy.

\begin{tabular}{ll}
\hline Affected drug & Interfering drugs \\
\hline Phenobarbitone & $\begin{array}{l}\text { Chloramphenicol, dicoumarol, frusemide, } \\
\text { methysuximide, methylphenidate, phenytoin, } \\
\text { sulthiame, valproic acid }\end{array}$ \\
Primidone & Sulthiame, isoniazid \\
Carbamazepine & Propoxyphene, triacetyloleandomycin \\
$\begin{array}{l}\text { Diazepam and some } \\
\text { other benzodiazepines }\end{array}$ & Disulfiram \\
\hline
\end{tabular}

Table s - Potential interactions resulting in inhibition of metabolism, increased serum levels and increased pharmacological activity of other antiepileptic drugs.

An interaction which seems to be particularly important from the clinical point of view occurs between propoxyphene and carbamazepine. Dam et al (1977) reported a marked rise $(45-77$ per cent) in serum carbamazepine levels after seven patients with epilepsy or trigeminal neuralgia were given propoxyphene hydrochloride, $65 \mathrm{mg}$ t.d.s. Drowsiness, dizziness, headache and other adverse effects developed in most subjects and were sufficiently severe to require discontinuation of propoxyphene in two.

Induction of metabolism - Phenytoin, phenobarbitone, primidone and carbamazepine are potent inducers of the hepatic microsomal drug-metabolizing enzymes (1978 Perucca et al, 1979; Perucca). When these agents are used in combination with other antiepiletic drugs, stimulation of metabolism may occur, which results in decreased steady-state serum levels of the affected drug. The clinical importance of these interactions is generally small because the (usually) reduced pharmacological effect of the affected drug is compensated for by the added therapeutic effect of the interfering agent. In other cases, stimulation of metabolism may result in increased formation of active metabolites 
with long half-lives. The overall result of latter type of interaction can be a potentiation rather than a reduction of the pharmacological effect of the affectea drug: a possible good example is the phenytoin-induced stimulation of the conversion of primidone to phenobarbitone.

Probably the most important of the interactions resulting in induced metabolism of antiepileptic drugs is the marked stimulation of carbamazepine metabolism in patients treated with phenytoin, phenobarbitone or primidone in combination. On average, serum carbamazepine levels in patients receiving combination therapy are $50-100$ per cent lower than in patients treated with equivalent doses of carbamazepine alone. This interactions is likely to have considerably clinical importance: for example, it is probably responsible for the lower prevalence of carbamazepine-induced hyponatriaemia and water intoxication in patients receiving phenytoin in combination (Fig. 3).

Interactions affecting renal excretion - None of the major antiepileptic drugs are excreted unchanged in urine to any important extent, with the possible exception of phenobarbitone. Drugs which alkalinize the urine may reduce

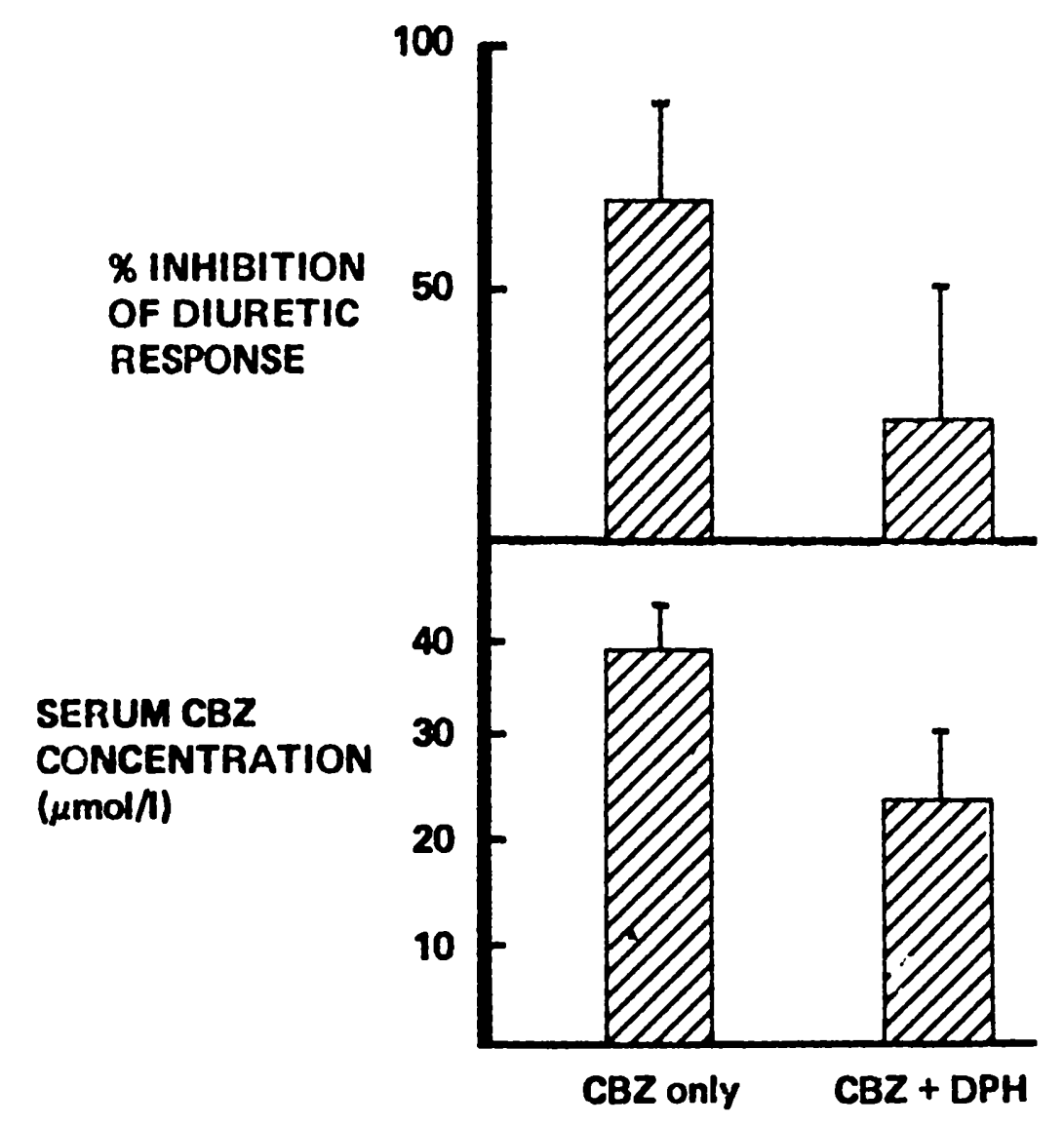

Fig. $s$ - Impairment of the excretion of a standard water load (expressed as per cent inhibition of water excretion compared to a normal population) in patiente treated with carbamasepine; either alone or in combination with phonytoin. The carbamasepine dose was equivalent in both oroups $(n=6$ for each group). Note the markedly lower serum consentration and antidiuretic effect of carbamasepine in phonytoin treated patients. 
the tubular resorption of phenobarbitone and thereby increase its rate of excretion in urine. This observations has led to the use of sodium bicarbonate in the management of barbiturate overdose.

Pharmacodynamic interactions - Clinically important interactions may occur even in absence of any significant change in the concentration of the interacting drugs in plasma. Many of these interactions are thought to occur at the receptor site and are classified as pharmacodynamic. Many antiepileptic drugs, for example, have a depressant action on the central nervous system (CNS) which can be additive or even show reciprocal potentiation when these agents are used together. Thus, patients receiving two or more antiepileptic drugs in combination can show toxic signs in spite of low serum concentration values of the individual agents. Other examples include the reciprocal potentiation of the CNS adverse effects of antihistamines, alcohol and barbiturates and the greater risk of respiratory arrest when intravenous diazepam and phenobarbitone are combined in the treatment of status epilepticus.

\section{INTERACTIONS AFFECTING HANDLING AND RESPONSE TO OTHER DRUGS}

Absorption interactions - The effect of antiepileptic drugs on the gastrointestinal absorption of other drugs has been little investigated despite evidence that this can be a fruitful area for research. The absorption of griseofulvin is reduced in patients treated with phenobarbitone resulting in clinical ineffectiveness of standard doses of this antifungal agent when given together with phenobarbitone. In a similar way, phenytoin can reduce the absorption of frusemide, thus providing a partial explanation for the abnormally reduced diuretic response to oral frusemide in patients treated with antiepileptic drugs.

Plasma protein binding interactions - Trichloroacetic acid (TCA), the main metabolite of chloral hydrate in man, displaces warfarin from plasma protein binding sites and can potentiate the hypoprothrombinaemic effects of the latter drug.

Induction of metabolism It has been mentioned above that phenytoin, phenobarbitone, primidone and carbamazepine are potent inducers of the hepatic drug-metabolizing enzymes. As a result, the metabolism of a large number of concurrently administered drugs can be considerably accelerated in epileptic patients. In some cases the therapeutic consequences of the interaction will be negligible; in others it will be disastrous unless appropriate adjustments in dosage are made. The best know example of this type of interaction involves oral anticoagulants: patients treated with phenytoin, barbiturates and carbamazepine require for satisfactory anticoagulant control doses of warfarin which are larger than usual. A dangerous time comes when the major anticonvulsants are withdrawn, or their dose is reduced, or they are substituted for by other antiepileptic drugs (e.g. valproic acid, ethosuximide, benzodiazepines) which have no enzyme-inducing properties: the metabolism of the anticoagulant will show and it will gradually accumulate in serum, and life threatening haemorrhage may occur if the dose is not correspondingly reduced. In an American series, 
as many as 15 out of 52 bleeding accidents were due to withdrawal of enzymeinducing drugs without a modification of the anticoagulant dose (MacDonald and Robinson, 1968).

Other important interactions involving stimulation of metabolism are not as widely recognised. For example, few clinicians appear to be aware of the reduced effectiveness of oral contraceptives in women taking antiepileptic drugs. In a recent series, phenobarbitone, phenytoin and carbamazepine were the drugs most frequently implicated in causing spotting and breakthrough bleeding in a large population of patients taking various psychotropic drugs in addition to oral contraceptives (Hempel and Klinger, 1976). Most likely the bleeding was a consequence of increased metabolic elimination of the hormonal steroids, and was an indication of reduced contraceptive efficacy. Stimulation of steroid hormone metabolism is responsible for the failure of the low-dose dexamethasone suppression test to suppress plasma and urinary corticosteroid levels in patients treated with phenytoin. The clinical efficacy of dexamethasone and prednisolone is also reduced in these patients. Another test of adrenal function, the inhibition of corticol production by oral metyrapone, is also ineffective during treatment with enzyme-inducing drugs, probably due to stimulation of metyrapone elimination during its first passage through the liver.

Table 4 lists a number of other agents whose metabolism has been reported to be stimulated by antiepileptic drugs. The clinical implications of these interactions are mostly unknow: in many cases they are probably small and insufficient to alter to an important extent the therapeutic response to standard doses of these drugs. When active or toxic metabolites are produced, stimulation of metabolism may potentiate the pharmacological activity and/or the toxicity of the affected drug: the latter may indeed be true for drugs such as paracetamol and pethidine.

\begin{tabular}{l||l}
\hline Antibiotics: & $\begin{array}{l}\text { Psychotropic drugs: } \\
\text { Chlorpromazine, dessmethylimipramine } \\
\text { Chloramphenicol. doxycycline }\end{array}$ \\
rifampicin & $\begin{array}{l}\text { imipramine, nortriptyline } \\
\text { Steroidal agents: } \\
\text { Cardiovascular drugs: } \\
\text { Alprenolol, digitoxin }\end{array}$ \\
lignocaine & $\begin{array}{l}\text { Cortisol, dexamethasone, methylprednisolone, } \\
\text { methyrapone, oral contraceptives, } \\
\text { Orednisolone, vitamina } \mathrm{D}_{3}\end{array}$ \\
Dicoumarol, warfarin & $\begin{array}{l}\text { Analgesic and anti-inflammatory drugs: } \\
\text { antipyrine, fenoprofen, paracetamol, } \\
\text { Miscellaneous: }\end{array}$ \\
DDT & phenylbutazone, pethidine \\
\hline
\end{tabular}

Table \&-Pharmacological agents whose rate of metabolism has been reported to be stimulated by antiepileptic drugs. 
Pharmacodynamic drug interactions - The diuretic response to intravenous frusemide is reduced in patients treated with antiepileptic drugs, possibly due to reduced renal sensitivity to the drug.

\section{SUMMARY AND CONCLUSIONS}

Interactions with antiepileptic drugs are common and may have important clinical consequences. The physician should always consider carefully the need for and the implications of adding a new drug to any therapeutic regime and should be prepared to think about the possibility of an interaction whenever an unusual response is seen. Serum drug levels can be an invaluable tool in the recognition and the management of most types of interactions, but in no case can they be a substitute for careful observations and evaluation of the patient's symptoms and physical findings.

\section{RESUMO E CONCLUSOES}

Interações com fármacos anticonvulsivantes são comuns e podem ter consequências clínicas importantes. $\mathrm{O}$ médico deve sempre cuidadosamente considerar a necessidade e as implicações da adição de uma nova droga a qualquer regime terapêutico, e deve estar preparado para pensar na possibilidade de uma interação sempre que uma resposta anormal for notada. Niveis séricos podem ser de valor inestimável no diagnóstico e na conduta da maior parte das interações, mas nunca substituem a cuidadosa observação e avaliação clínica.

\section{REFERENCES}

1. DAM, M.; KRISTENSEN, C. B.; HANSEN B. S. \& CHRISTIANSEN, J. - Interaction between carbamazepine and propoxyphene in man. Acta Neurol. Scand. $56: 693,1977$.

2. HEMPEL, E. \& KLINGER, W. - Drug-stimulated biotransformation of hormonal steroid contraceptives: clinical implications. Drugs 12:442, 1976.

3. HOUGHTON, G. W. \& RICHENS, A. - Phenytoin intoxication induced by sulthiame in epileptic patients. J. Neurol. Neurosurg. Psychiatr. 37:275, 1974.

4. KUTT, H. - Diphenylhydantoin: interactions with other drugs in man. In Antiepileptic Drugs - ed. Woodbury D.M., Penry, J.K. \& Schmidt, R.P. Raven Press, New York, 1972, pp. 169-180.

5. MAC DONALD, M. G. \& ROBINSON, D. S. - Clinical observations of possible barbiturate interference with anticoagulation. J.A.M.A. 204:97, 1968.

6. MATTSON, R. H.; CRAMER, J. A.; WILLIAMSON, P. D. \& NOVELLY, R. A. Valproic acid in epilepsy: clinical and pharmacological effects. Ann. Neurol. 3:20, 1978.

7. MURRAY, F. J. - Outbreak of unexpected reactions among epileptics taking isoniezid. Am. Rev. Resp. Dis. 86:729, 1962. 
8. PERUCCA, E. - Clinical consequences of microsomal enzyme-induction by antiepileptic drugs. Pharmacol. Ther. C. 2:285-314, 1978.

9. PERUCCA, E. - Antiepileptic druy interactions. In A Textbook of Epilepsy ed. Laidlaw, J. \& Richens, A. Churchill-Livingstone, Edinburgh, 1980 (in press).

10. PERUCC , E.; HEDGES, A. M.; MAKRI, K.; HEBDIGE, S.; WADSWORTH, J. \& RICHENS, A. - The comparative enzyme-injucing properties of antiepileptic drugs. Brit. J. clin. Pharmacol. 7:414, 1979.

11. PERUCCA, E. \& RICHERS, A. - Anticonvulsant drug interactions in epilepsy. In Current Status of Modern Therapy - ed. Tyrer, J. MTP Press, Lancaster, 1980 (in press).

12. RICHGNS, A. - Interactions with antiepileptic drugs. Drugs 13:266, 1977.

Clinical Pharmacology Unit - Institute of Neurology - National Hospital Queen Square - London WC1N sBG. Enoland. 